\title{
Introdução à lógica de programação no ensino fundamental: uma análise da experiência de alunas com Code.org
}

\author{
Maria Victoria Soares Fiori, Marina da Silva Rocha, Karina Castelo Branco, Anna \\ Beatriz Marques
}

\author{
Universidade Federal do Ceará (UFC) Campus Russas \\ CEP 62900-000 - Russas - CE - Brasil \\ \{victoria.fiori, marinarocha, karinascb\}@alu.ufc.br, beatriz.marques@ufc.br
}

\begin{abstract}
Computational thinking and logical reasoning increase the ability to deduce and solve problems, and their learning is important in the early school years. This fact motivated the experience of introducing concepts of programming logic in elementary school. For that, an experience with the Code.org platform is presented with 91 students, 45 girls, from the final years of elementary school (6th and 7th year). In this article, we will focus on analyzing the experience of using the platform from the students' point of view. The objective of the experiment was to present basic programming commands, offering students mechanisms to solve challenges. To evaluate this experience, a questionnaire provided by the MEEGA + KIDS model was used.

Resumo. Pensamento computacional e o raciocínio lógico aumentam a capacidade de deduções e resoluções de problemas, sendo importante o seu aprendizado nos primeiros anos escolares. Esse fato, motivou a experiência de introdução de conceitos de lógica de programação no ensino fundamental. Para isso apresenta-se uma experiência com a plataforma Code.org com 91 estudantes, sendo 45 meninas, dos anos finais do ensino fundamental ( $6^{\circ}$ e $7^{\circ}$ ano). Neste artigo, focaremos na análise da experiência do uso da plataforma do ponto de vista das alunas. O objetivo da experiência foi apresentar comandos básicos de programação, oferecendo aos estudantes mecanismos para a resolução de desafios. Para avaliar essa experiência foi utilizado um questionário fornecido pelo modelo MEEGA+KIDS.
\end{abstract}

\section{Introdução}

O cenário educacional está cada vez mais dinâmico e desafiador. Grandes avanços surgiram na área da tecnologia e o maior acesso às ferramentas disponíveis no ambiente virtual. Estes recursos computacionais devem ser utilizados a favor da escolarização dos estudantes sem distinção de idade ou público. O processo de inclusão digital deveria ser iniciado nos primeiros anos da formação escolar, proporcionando práticas com atividades ligadas à ciência da computação que podem possibilitar aos estudantes o aprendizado de programação básica, familiarizá-los com o assunto [Martins et al. 2016].

Entretanto, no Brasil esta prática ainda é rara nas escolas, principalmente nos anos iniciais de ensino. Os estudantes costumam ter contato com tecnologias desde cedo, entretanto não tem acesso ao ensino de computação, o que resulta na falta de interesse e desconhecimento do tema por partes dos profissionais das escolas e até mesmo dos estudantes.

Nos últimos anos tem-se observado uma queda na procura por cursos de Ciência da Computação e áreas correlatas [De Oliveira et al., 2018]. A redução do número de mulheres interessadas na carreira computacional é ainda mais significativa. De Holanda et al. (2017) afirmam que ações para alunas do ensino fundamental devem ter um efeito mais produtivo do que no ensino médio, pois nota-se que no ensino médio muitas meninas já estão com suas 
decisões tomadas. Pensando nisso, o foco deste trabalho foi direcionado para a avaliação da experiência do público feminino com a plataforma Code.org, partindo do princípio de entender como as mesmas reagem com o contato com jogo, se a plataforma é adequada para promover uma boa experiência às meninas e aproximá-las da área de Computação.

Esta ação resultou na participação de 91 estudantes, sendo 45 meninas. Todos faziam parte do ensino fundamental, sendo 21 alunas do $6^{\circ}$ e 24 alunas do $7^{\circ}$ ano de uma escola privada da cidade de Russas. Para avaliar o uso da plataforma com os estudantes e considerando sua faixa etária, foi adotado o questionário do modelo MEEGA+ Kids [Gresse von Wangenheim et al. 2018], que avalia a experiência do jogador e a usabilidade de jogos direcionados ao ensino de Computação e utilizados por estudantes da educação básica. As próximas seções deste artigo estão organizadas da seguinte maneira: a Seção 2 apresenta a plataforma Code.org e trabalhos relacionados.

A Seção 3 apresenta a metodologia adotada. Na Seção 4 são apresentados os resultados obtidos por meio do MEEGA+ Kids. Por fim, na Seção 5 são apresentadas as conclusões e trabalhos futuros.

\section{Code.org e trabalhos relacionados}

A plataforma Code.org tem o objetivo de propagar conceitos básicos de Ciência da Computação para mulheres e minorias não representadas em instituições de ensino. Seu principal projeto "A Hora do Código" consiste em estimular voluntários a doar uma hora do seu dia para ensinar aos estudantes da educação básica noções de programação, como condicionais e laços de repetição, através dos jogos disponibilizados na plataforma [Martins et al. 2016].

Diante disso, promover a interação social entre os estudantes e o jogo, a troca de perspectivas para resolução de um problema de forma colaborativa, proporcionando um maior engajamento entre eles, por meio de um material de qualidade que permite que todos tenham acesso, sendo assim democratizando o ensino de conceitos básicos de ciência da computação.

Em relação a outros relatos de experiência sobre o uso do Code.org na educação básica, Fiori et al. (2019) realizaram uma experiência com Code.org no ensino médio que conta com a participação de meninos e meninas para analisar a percepção dos estudantes por gênero, no qual obtiveram resultados relevantes sobre a experiência do jogador. $\mathrm{O}$ trabalho de Freitas et al. (2019) analisa o desenvolvimento do pensamento computacional no ensino fundamental por meio de aulas com jogos do Code.org, no qual os resultados obtidos mostraram o interesse dos alunos, estimulando uma aprendizagem tecnológica construtiva.

Com base nisso, a realização deste trabalho é similar aos relatados porque busca fomentar o conhecimento sobre programação dos estudantes do ensino fundamental. $\mathrm{O}$ diferencial deste artigo é analisar os dados sobre a experiência das meninas e sua interação com a plataforma Code.org, investigando se a plataforma promove uma boa experiência de aprendizado.

\section{Metodologia}

A metodologia adotada nesta pesquisa foi o estudo de caso. A experiência com Code.org ocorreu em um colégio do ensino privado da cidade de Russas com 91 estudantes com duração de dois dias devido a turma ser pequena. $\mathrm{O}$ estudo foi conduzido no laboratório do colégio que contava com computadores e um projetor. No primeiro dia, a experiência foi realizada com os estudantes do $6^{\circ}$ ano (turma A e B) e no segundo dia, com os estudantes do $7^{\circ}$ ano (turma $\mathrm{A} \mathrm{e}$ B). A experiência durou em média 1 h 40 minutos em ambos os dias, cada ação durou 50 
minutos por turma. Os procedimentos metodológicos adotados em ambos os dias foram similares, resumidamente descritos a seguir.

Explicação do objetivo do projeto: O processo metodológico foi iniciado explicado o objetivo do projeto de extensão Meninas Digitais do Vale e o impacto da Computação na sociedade.

Introdução de conceitos básicos de programação: As alunas responsáveis pela ação em questão, explicaram conceitos básicos de lógica de programação como: variáveis, comando, laços de repetição e condicionais para os estudantes.

Apresentação da plataforma Code.org: foi apresentado aos estudantes a plataforma Code.org e os estudantes foram instruídos sobre como utilizá-la.

Utilização da plataforma: Após a apresentação, foi iniciado o uso da plataforma Code.org pelos estudantes, o jogo foi utilizado individualmente em computadores no laboratório do colégio. Se houvessem dúvidas, os estudantes poderiam solicitar a ajuda das alunas responsáveis. O jogo utilizado foi o "Minecraft Aventureiro" pois, é muito famoso entre as crianças e os pré-adolescentes, que contribui para concentração dos participantes.

Aplicação do questionário: Ao fim da utilização do jogo os alunos responderam ao questionário de avaliação da experiência. Para avaliar a qualidade do jogo em termos de experiência do jogador e percepção da aprendizagem do ponto de vista dos estudantes, foi aplicado o modelo de questionário do MEEGA+Kids. O MEEGA+Kids foi proposto por Gresse von Wangenheim et al. (2018) para avaliar jogos educacionais em Computação com estudantes da educação básica.

\section{Análise dos resultados}

A experiência das jogadoras (Figura 4 e Figura 5) está relacionada com a experiência proporcionada pelo jogo ao jogador. Para Costa \& Nakamura (2015), é importante salientar que além da interação entre o jogador e o jogo, a experiência do jogador é afetada por fatores como narrativa, aspectos visuais e sociais, de maneira que mesmo que o jogo satisfaça as dimensões: satisfação, aprendizado, efetividade, imersão, motivação, emoção e socialização, a avaliação da experiência do jogador pode ser negativa.

Dimensão de confiança: a dimensão de confiança demonstra alto nível de confiança das estudantes com os conteúdos aplicados no jogo.

Dimensão de desafio: Nota-se que as estudantes consideraram o jogo desafiador e que o mesmo propõe diferentes desafios a cada fase em um ritmo adequado.

Dimensão de satisfação: Esses resultados demonstram que mais da metade das estudantes consideram as tarefas proposta pelo jogo monótonas, porém a maioria dos estudantes se sentiram satisfeitas ao realizar tarefas e atribuem o seu sucesso a sí, devido aos conhecimentos adquiridos na experiência.

Dimensão de interação social: Nota-se que na primeira e terceira afirmativa, as estudantes alcançaram um alto nível de concordância, porém na segunda afirmativa elas se mostram menos satisfeitas, pois as tarefas foram realizadas individualmente, portanto é necessário pensar em medidas para melhoria da interação social na execução da experiência e no jogo.

Dimensão diversão: Os dados demonstram que as estudantes se divertiram na realização da experiência. 


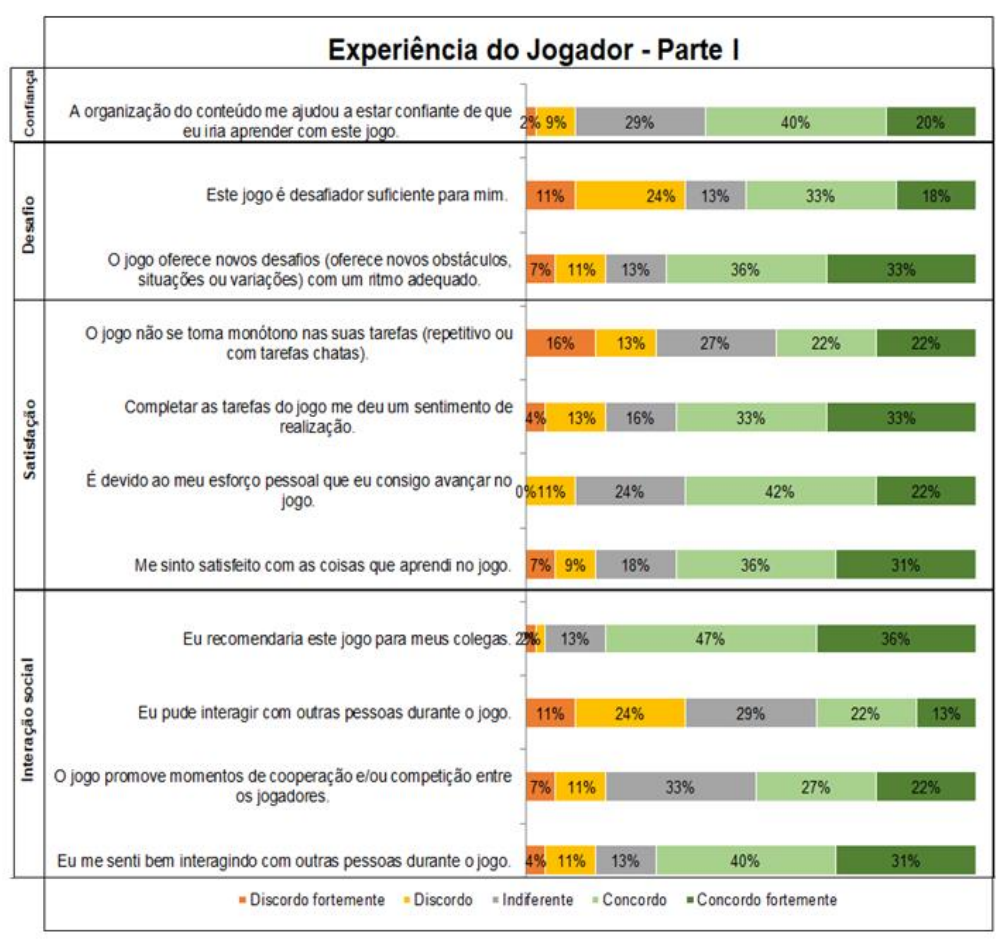

Figura 4. Gráfico de experiência do jogador - Parte I.

Dimensão atenção focada: As estudantes demonstram um nível razoável de atenção focada durante o jogo.

Dimensão de relevância: É notório que houve uma discrepância entre os resultados da primeira e a terceira afirmativa com o resultado da segunda afirmativa. Contudo, estudantes mostram que compreenderam que os assuntos explicados na aula introdutória estavam relacionados ao jogo e tiveram absorção do conteúdo.

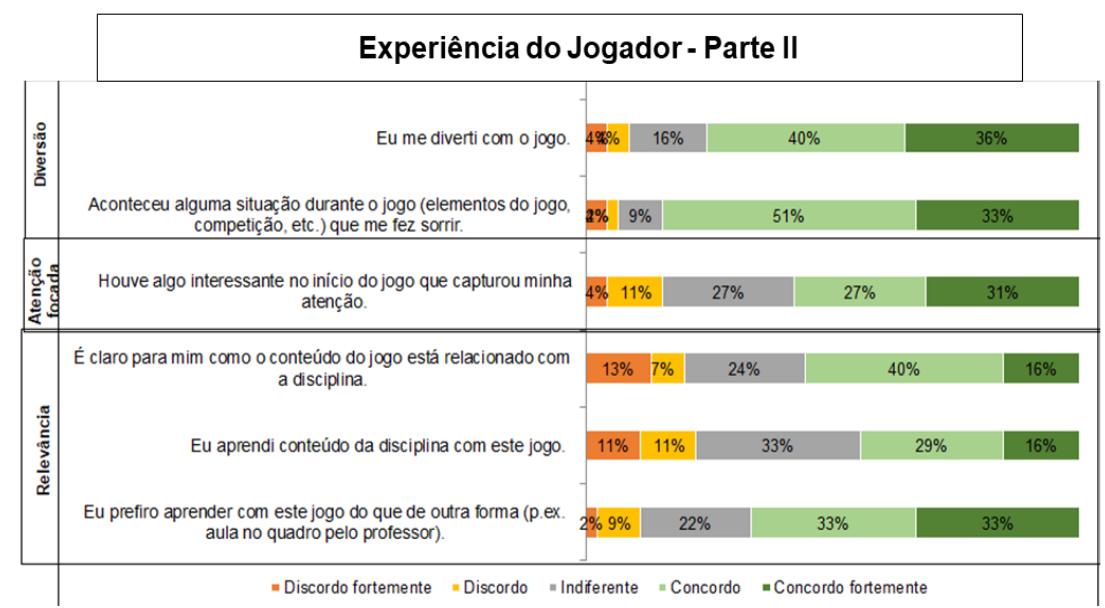

Figura 5. Gráfico de experiência do jogador- Parte II.

\section{Considerações finais}

Este trabalho teve como principal objetivo introduzir conceitos básicos de ciência da computação para estudantes da educação básica, outrossim as ações foram ministradas por alunas bolsistas do projeto de extensão Meninas Digitais do Vale, fator que contribuiu para salientar que as mulheres estão presente na área de Computação. 
Os resultados da avaliação do jogo em relação às dimensões como diversão e confiança, obtiveram alto percentual de concordância em suas afirmativas. Contudo, observou-se que a dimensão de relevância apontou uma necessidade de melhoria no ensino dos conceitos na aula introdutória, fato que pode ter ocorrido pela forma que afirmativa "o conteúdo tem a ver com a disciplina" foi escrita que levou as estudantes a associarem com a disciplina que cedeu o horário para realização da ação e não ao ensino de programação. Além disso, na dimensão desafio notou-se um percentual significativo de que o jogo não foi desafiador para as estudantes. Portanto, nas experiências futuras, outros jogos serão investigados e experimentados.

\section{Referências}

Costa, A. F., \& Nakamura, R. (2015). Experiência de usuário e experiência de jogador: discussão sobre os conceitos e sua avaliação no projeto de jogos digitais. Proceedings do Simpósio Brasileiro de Jogos e Entretenimento Digital SBGames 2015, 512-517.

De Holanda, M. T., Mourão, R., Ramos, G. N., de Araújo, A. P. F., \& Walter, M. E. T. (2017). Uma pesquisa com alunas do ensino fundamental e médio sobre os cursos da Área de computação. In Anais do XI Women in Information Technology. SBC.

De Oliveira, E. R., Santos, N. V., \& de Almeida, D. A. G. (2018). Computação Para Todos na Escola: Relato de Experiência com alunas. In X Congreso de la Mujer Latinoamericana en Computación (LAWCC), Sao Paulo, Brazil.

Fiori, M., Rocha, M., \& Marques, A. (2019). Uma experiência de aprendizagem de lógica de programação com Code. org no ensino médio: uma análise por gênero sobre a percepção dos estudantes. In Anais do XIII Women in Information Technology (pp. 124-128). SBC.

Freitas, M., \& Morais, P. (2019). Possibilidade de desenvolvimento do Pensamento Computacional por meio do CODE. ORG: aplicado ao Ensino Fundamental (anos iniciais). In Anais do Workshop de Informática na Escola (Vol. 25, No. 1, p. 1219).

Gresse von Wangenheim, Christiane \& Petri, Giani \& Borgatto, Adriano. (2018). MEEGA+KIDS: A Model for the Evaluation of Educational Games for Computing Education in Secondary School. Relatório Técnico. 